\title{
La aparente actualidad en el debate sobre los inmigrantes y refugiados*
}

\author{
Paz Molero Hernández
}

Recibido: 30 de marzo de 2016 - Aprobado: 26 de mayo de 2016

\section{Resumen}

En este trabajo se analiza si las raíces de la crisis actual de los refugiados e inmigrantes son propias de nuestro tiempo. Para ello, se compara con otra crisis que tuvo lugar en Europa en el siglo xvi, a raíz de la prohibición de la mendicidad, concretamente en España, en 1545. En ese año se aprobaron un conjunto de disposiciones jurídicas que seguían, a su vez, un movimiento que se estaba difundiendo en toda Europa para regular el ejercicio de la limosna y prohibir una costumbre hasta entonces bastante tolerada: la mendicidad. Domingo de Soto, dominico y uno de los principales integrantes de la Escuela de Salamanca, publicó un comentario titulado Deliberación sobre la causa de los pobres, a la que replicó, poco tiempo después, el benedictino Juan de Robles, dando lugar entonces a lo que se llamó "El debate sobre los pobres". Se analiza también si las claves del problema son propias de nuestro tiempo o si se repiten $\mathrm{y}$, por último, sin dar una solución concreta - porque dadas las dimensiones del problema parece imposible - se intenta dar luces para la reflexión de las distintas alternativas y posibilidades que se abren ante esta crisis humanitaria.

Palabras clave: debate sobre los pobres, inmigrantes, refugiados, Domingo de Soto, Juan de Robles.

\footnotetext{
Artículo de reflexión. El presente trabajo surge de las líneas de investigación sobre Historia del Pensamiento Económico, del Instituto de Investigación Market, Culture and Ethics, Universidad de la Santa Croce, Roma, Italia. Este artículo no hubiera podido ser escrito sin los sabios consejos y sugerencias del profesor Martin Schlag y del Instituto de Investigación Market, Culture and Ethics, a los que agradezco muy sinceramente su apoyo en mi labor científica. DOI: http://dx.doi. org/10.15332/s0120-8454.2016.0089.01

* Doctora en Teología, profesora de Antropología y Ética. Directora de Ordenación Académica del Centro Universitario Villanueva, adscrito a la Universidad Complutense de Madrid. Dirección postal: Claudio Coello 11, 28001, Madrid, España. Correo electrónico: pmolero@villanueva.edu
} 


\title{
The apparent topicality in the debate about immigrants and refugees*
}

\author{
Paz Molero Hernández**
}

\section{A bstract}

The present paper analyses whether the roots of the current refugee and immigrant crisis are characteristic of our time. To this end, this crisis is compared with the one that took place in Europe during the $16^{\text {th }}$ century, as a consequence of the ban on vagrancy, more specifically in Spain, in 1545. In that year, a series of juridical dispositions were passed following a movement that spread all over Europe to regulate the asking and giving of alms and to prohibit a custom that, up to that time, was tolerated to a certain extent: vagrancy. Domingo de Soto, a Dominican friar and one of the most prominent members of the School of Salamanca, published a comment titled Deliberación sobre la causa de los pobres (Discussion on the cause of the poor), which was replied soon after by the Benedictine monk Juan de Robles. The controversy gave rise to what was called "The debate on the poor". The paper also analyses whether the keys to the interpretation of the problem are specific of our time or just a repetition. Finally, although a specific solution is not pointed out - given the dimensions of the problem, that seems impossible-, the paper tries to shed light on the discussion of the different alternatives and possibilities open to this humanitarian crisis.

Keywords: Debate on poor relief, inmigrants, refugees, Domingo de Soto, Juan de Robles.

Reflection paper. This work arises from the research on History of Economic Thought, from the Market, Culture and Ethics Research center of the Pontifical University of the Holy Cross, Rome, Italy. This paper would not have been written without the wise advice and suggestions of Professor Martin Schlag and of the Market, Culture and Ethics Research center, to whom I sincerely express my gratitude for their support to my scientific work. DOI: http://dx.doi.org/10.15332/ s0120-8454.2016.0089.01

* Doctor of Theology, Professor of Anthropology and Ethics. Director of Academic Planning in Centro Universitario Villanueva, attached to Universidad Complutense in Madrid. Address: Claudio Coello 11, 28001, Madrid, Spain. Email: pmolero@villanueva.edu 


\title{
La prétendue actualité dans le débat sur les immigrants et refugiés*
}

\author{
Paz Molero Hernández ${ }^{* *}$
}

\section{Résumé}

Dans ce travail, on analyse si les racines de 1'actuelle crise des réfugiés et des migrants sont propres de notre temps. Pour cela, on la compare avec une autre crise qui s'est déroulée en Europe au XVI siècle, à la suite de l'interdiction de la mendicité en Espagne en 1545. Cette année-là, un ensemble de dispositions juridiques furent approuvées, suivant à leur tour, un mouvement qui était en train de se répandre dans toute l'Europe pour réguler l'exercice de l'aumône et interdire une coutume jusque-là plutôt tolérée: la mendicité. Domingo de Soto, moine dominicain et l'un des principaux intégrants de l'École de Salamanque, publia un commentaire intitulé, "Deliberación sobre la causa de los pobres", Délibération sur la cause des pauvres, auquel répondu, peu de temps après, le bénédictin Juan de Robles, donnant lieu ainsi à ce que l'on appela "Le débat sur les pauvres". On analyse également si les causes du problème sont propres de notre temps ou si elles se répètent et, enfin, sans donner une solution concrètecar vu les dimensions du problème cela paraît impossible- on essaye de donner des clés pour la réflexion des différentes alternatives et possibilités qui s'ouvrent face à cette crise humanitaire.

Mots clés: débat sur les pauvres, migrants, réfugiés, Domingo de Soto, Juan de Robles.

\footnotetext{
Article de réflexion. Le suivant travail surgit des domaines de recherche sur l'Histoire de la Pensée Économique de I'Institut de Recherche Market, Culture and Ethics, Université de la Santa Croce, Rome, Italie. Cet article n'aurait pas pu être écrit sans les savants conseils et suggestions du professeur Martin Schlag y de I'Institut de Recherche Market, Culture and Ethics, lesquels je remercie très sincèrement pour leur soutien dans mon travail scientifique. DOI: http:// dx.doi.org/10.15332/s0120-8454.2016.0089.01

* Docteur en Théologie, professeur d'Anthropologie et Éthique. Directrice d'Ordre Académique du Centre Universitaire Villanueva, assigné à l'Université Complutense de Madrid. Adresse postale: Claudio Coello 11, 28001, Madrid, Espagne. E-mail: pmolero@villanueva.edu
} 


\section{Introducción}

La crisis de los millones de refugiados, inmigrantes y desplazados está poniendo a prueba los pilares de la vieja Europa. Datos escalofriantes de personas que huyen de la represión en busca de una vida mejor son una muestra de esta hipótesis. Según las cifras que aportó el Alto Comisionado de las Naciones Unidas para los Refugiados (ACNUR), en los primeros seis meses de 2015, 137.000 refugiados y migrantes trataron de entrar en la UE, cantidad que representa un aumento del 83\% en el mismo periodo de 2014 (ACNUR, 2015).

En función de la rapidez del fenómeno, la gestión de inmigración y la acogida de refugiados en Europa se está llevando a cabo , de manera voluntarista y algo precipitada (Montoro, López y Pons, 2009). Hay cierta percepción, no solo por parte de los media, de soluciones transitorias y de cambios de leyes, según se sientan afectados los ciudadanos de los países de acogida.

Con miras a encontrar si las raíces de esta crisis son novedosas, se la compara con otra crisis que se dio en Europa en el siglo xvI, a raíz de la prohibición de la mendicidad en España, en 1545. Es el llamado "Debate sobre los pobres". En ese año se aprobaron un conjunto de disposiciones jurídicas que seguían, a su vez, un movimiento que se estaba difundiendo en toda Europa para regular el ejercicio de la limosna y prohibir una costumbre hasta entonces bastante tolerada: la mendicidad. Domingo de Soto, dominico y uno de los principales integrantes de la Escuela de Salamanca, publicó un comentario titulado Deliberación sobre la causa de los pobres, a la que replicó, poco tiempo después, el benedictino Juan de Robles.

Se analiza también si las claves del problema son propias de nuestro tiempo, o si estuvieron ya presentes en el citado debate del siglo xvI, y se intenta dar luces para la reflexión de las distintas alternativas y posibilidades que se abren ante esta crisis humanitaria (sin dar una solución concreta, porque dadas las dimensiones del problema parece imposible).

\section{La prohibición de la mendicidad en España. Breve contexto histórico}

El siglo xvi en España fue un momento de crecimiento económico. La delimitación del espacio de actuación por el Tratado de Tordesillas, de 1493, conllevó a la conquista del territorio americano y, a su vez, a la ordenación económica de un territorio cada vez más amplio. Al cabo de unos años de la conquista de América, se irían viendo las consecuencias económicas, especialmente bajo la forma de unas riquezas metálicas, que irían convirtiéndose en el pilar fundamental de la política imperial española durante este siglo.

La afluencia de metal alteró el panorama financiero. Se calcula que solo en el siglo xvi llegó a España más del triple de la reserva de planta preexistente y 
una quinta parte del oro. Como consecuencia lógica, el metal predominante fue la plata frente al oro, y a mediano plazo se empezarían a oír quejas debido al incremento de los precios, sobre todo por una ausencia de precedentes y de mecanismos correctores. Al no subir los salarios en la misma proporción, bajó el poder adquisitivo de la población trabajadora y aumentaron los beneficios empresariales. No es extraño que al acercarse el coste de producción al precio de venta, la población rural - que en ese momento era la mayor parte de la población - emigrara hacia la ciudad, con la esperanza de obtener mejores condiciones de vida.

Toda España disponía de espacios vacíos o semivacíos en los que poder colocar un eventual incremento demográfico, todo ello enmarcado en una alta fecundidad pero también una tasa de mortalidad elevada. De hecho, la esperanza de vida se sitúa en los 26,8 años, organizada alrededor de familias de 4 o 5 miembros supervivientes. (González Enciso, 1992, p. 72)

El problema aparece cuando las ciudades empiezan a saturar su capacidad para absorber la oferta de trabajo. A todo esto hay que añadir las obligaciones financieras derivadas de la política exterior que llevan a cabo los monarcas españoles con los banqueros genoveses, alemanes y flamencos. Como consecuencia, la enorme masa de metales que se recibió se dirigió a los mercados europeos para compensar el déficit o para financiar la política bélica.

La ausencia de condiciones higiénicas sanitarias suficientes y la propagación de enfermedades contagiosas derivadas de esa escasez, junto con los cambios climáticos en la meseta castellana, que dieron lugar a hambrunas y a la aparición en las ciudades de numerosos mendigos, son algunos de los factores cuya concatenación llevó al aumento del pauperismo. Aunque no hay constancia de censos generalizados de pobres hasta el siglo xviII, el número debió ser tan elevado que obligó a los distintos responsables a buscar soluciones.

En lo que coinciden los distintos estudios de historia social es en afirmar que, a partir del momento histórico en el que aparecen todas estas circunstancias, las prácticas caritativas realizadas por los distintos estamentos en el medioevo, comienzan a ser criticadas, en el siglo XVI, por su incapacidad para hacer frente a la pauperización y al desempleo de buena parte de la sociedad. (Garrán Martínez, 2004, p. 30)

Es entonces cuando empiezan a promulgarse una serie de reglamentaciones (entre otras, la de mayor relevancia será el Ordenamiento de pobres en Zamora, copiado y llevado a la práctica poco después en Salamanca y Valladolid), no solo en España, sino en distintas ciudades europeas, donde la burguesía y la nobleza se iban sintiendo abrumadas por el aumento ingente de pobres. Las distintas disposiciones, municipales y de las más altas instancias legislativas, configuraron una materia jurídica que se llamó popularmente "leyes de los pobres". 
En España, en concreto, los representantes municipales venían reclamando medidas drásticas desde hacía tiempo. La respuesta emitida por el emperador Carlos V sobre esta problemática fue la Pragmática Real del 24 de agosto de 1540. En ella se apuesta por la intervención del poder político y por la racionalización del sistema de ayuda. Prohibía mendigar, so pena de castigo, a los que estaban capacitados y ordenaba que los verdaderos pobres fueran atendidos por sus obispos, de igual modo que se hacía ya en las ciudades flamencas. La condición para poder mendigar era investigar y confirmar la pobreza. Se prohibía a su vez a los peregrinos que salieran de Santiago - que era el lugar al que se peregrinaba-. Tras esta pragmática late el problema de la reforma hospitalaria - que empezaba a ser candente-, sobre la cual se legislaría y se introducirán reformas en las décadas siguientes. Se añadió a ella una Instrucción para poder llevarla a la práctica y ambas fueron publicadas en 1544, tal como indica el propio Domingo de Soto (DS) en su obra de 1545 (2006), cuyo origen radica en este conjunto de disposiciones jurídicas.

Al mes y medio de ser publicada la obra de Ds, Deliberación sobre la causa de los pobres, se divulga el breve escrito de Juan de Robles (JR): De la orden de que en algunos pueblos de España se ha puesto en la limosna para remedio de los verdaderos pobres. ${ }^{1}$ En este opúsculo, JR no citó expresamente la obra de DS, pero la elaboró intentando responder con sus propuestas a los muchos argumentos que allí aparecen. Una vez finalizada la polémica doctrinal, y tras adoptar las autoridades políticas las medidas aconsejadas por Ds, el espíritu de la pragmática quedó arrinconado durante mucho tiempo.

\section{El debate sobre los pobres}

\section{Antecedentes doctrinales de la controversia: Lutero y Luis Vives}

En el resto de Europa, también se había vivido una penosa situación social, que desde el siglo xiv había llevado a legislar una serie de normas jurídicas para prohibir la mendicidad y expulsar de las ciudades a los pobres no naturales, al mismo tiempo que para hacer trabajar a los falsos pobres (Fatica, 1992). Desde distintos puntos se estaba llegando a una toma de conciencia general, en la que se encontraban, en un horizonte común, tanto los intereses económicos de las clases urbanas, la búsqueda de soluciones a los problemas de falta de salubridad, la crítica social de los humanistas y las inquietudes religiosas de la reforma tanto católica como protestante. Se llamó Ley de Tavera, porque fue este cardenal, diplomático y hombre de gobierno, el que fue alentado por el propio
monarca a promulgar las medidas más convenientes y aplicar las reformas. Parece que fue él también quien pidió su parecer a Domingo de Soto y a Juan de Robles (Santolaria Sierra, 2003). 
La mala cosecha de principios de siglo xvi, que tuvo dimensiones generales en toda Europa, fue probablemente lo que disparó la salida de la carrera reformista. En general, la política que se llevó a cabo tenía un programa casi idéntico, caracterizado por un intento de organización racional de la asistencia, en busca de efectividad, muy acorde con la mentalidad moderna y por la secularización de la administración, distribución y control de fondos. Estas dos características suponían una importante reducción de las actividades caritativas que, hasta entonces, había desempeñado la Iglesia. Había una tercera característica, que consistía en querer realizar una clasificación de los pobres entre los que debían recibir asistencia y los que no, porque podían trabajar. Es decir, se pretendía la prohibición de la mendicidad pública. Una última nota, la defensa del trabajo como método terapéutico por excelencia para salir de esa situación de pobreza, era también una característica general a las distintas políticas.

Aunque casi toda esta reforma tenía un carácter urbano y fue llevada a cabo por los poderes municipales, fue apoyada por el poder estatal al ir acompaña de la promulgación de diversos edictos. De un modo claro ocurrió en las zonas de influencia protestante - las primeras directrices de la reforma luterana contenían una política social secularizada en materia de asistencia a los pobres- pero también en zonas católicas. (Santolaria Sierra, 2003, p. 16)

En efecto, a principios del siglo xvi, la Iglesia católica tenía regulada no solo la liturgia, el matrimonio y la vida moral, sino también el cuidado de los pobres y de los que padecían necesidades materiales. "El cristianismo en todas sus formas, como el judaísmo del que procede, enfatizó desde el principio la obligación de cuidar al pobre, al enfermo, a las viudas y huérfanos" (Berman, 2009, p. 189). Este cuidado requería que los párrocos asignaran una cantidad al cuidado del pobre, que los monasterios dieran comida, refugio y ropa, y que los laicos de buena posición - príncipes, reyes - hicieran donaciones a instituciones caritativas de todo tipo. Se exigía que, al menos, un cuarto de los ingresos fuera destinado a este objetivo. Se crearon en numerosas ciudades hermandades y cofradías de laicos, que tenían como finalidad desarrollar las obras de misericordia, siguiendo los dictados de la Iglesia católica. Pero cuando esa reforma fue apoyada también por miembros de la jerarquía católica, no tardaron en venir las críticas, en gran parte por la supuesta doctrina "herética" en la que se apoyaba esta reforma.

Con la reforma luterana, en Alemania, por ejemplo, se transfirió lo que hasta entonces hacían los párrocos y monasterios a las autoridades seculares. Es decir, correspondía ahora a estas la obligación de regular, financiar y administrar las actividades caritativas. La teología luterana sobre la asistencia a los pobres difería de las medidas adoptadas por la Iglesia católica, básicamente en tres aspectos. El primero, que se pretendía dar responsabilidad a la comunidad entera en la ayuda a necesitado y no solo a las autoridades eclesiásticas; el segundo, que se desplaza a la autoridad local la responsabilidad de regular esta responsabilidad; y el tercero, que era menos tolerante respecto a los pecados de gula y de pereza que se identificaban con varias formas de pobreza. 
Fue principalmente Lutero el que consiguió que se cumplieran estas obligaciones y el que llevó la iniciativa para hacer un boceto de ley que unificara las distintas leyes sobre asistencia de los pobres que habían sido adoptadas en diversas ciudades alemanas (Berman, 2009). Y fue también Lutero el que denunció con enorme fuerza el mal uso que hacían los eclesiásticos de los diezmos y limosnas, y quien propuso la secularización como modo de asestar un golpe a la Iglesia de Roma. Si bien en Alemania empezó el movimiento reformista urbano antes de que Lutero rompiera con Roma en 1521, este tuvo lugar, sobre todo, en las ciudades donde existía un buen grupo de proluteranos.

Casi en los mismos años, en 1526, Luis Vives publica El socorro de los pobres. Toda la obra es una invitación a las autoridades de Brujas a que intervengan en el problema de la pobreza y la mendicidad que allí, como en otras muchas ciudades, presentaba síntomas de gravedad y peligrosidad. Las reformas que propone hay que enmarcarlas en lo que se venía haciendo en el resto de Europa, no solo por parte de los eclesiásticos, sino de las autoridades civiles, promovidas por los humanistas. Su filosofía se caracteriza por su pragmatismo, y en esta obra en concreto, más que humanismo, "se podría decir que es 'humanitarismo', es decir, preocupación por el hombre, por su dolor y miseria tanto material como espiritual, tratando de eliminarla o aliviarla" (Vives, 2007, p. 9). Fue especialmente defensor del trabajo como medio para salir de las situaciones de penuria económica, así como crítico de la mala administración que algunos cargos eclesiásticos hacían de los bienes destinados para paliar la pobreza de los necesitados.

En general, parece que existió una coincidencia bastante amplia entre las autoridades políticas europeas sobre el modo de abordar el pauperismo. Inspiradas en doctrinas sociales de carácter reformista, parece que todas ellas coincidían en la imprescindible diferenciación entre pobres verdaderos y falsos, la preocupación por restringir sus movimientos migratorios y la prohibición de la mendicidad.

\section{Domingo de Soto y Juan de Robles}

Es en este marco donde España promulga también sus leyes de los pobres. Como se ha dicho, el más claro opositor a la reforma de las leyes sobre los pobres será DS y, en cambio, JR será partidario de la doctrina defendida por Luis Vives. La controversia entre ambas posturas es conocida con el nombre de "Debate sobre los pobres". Las distintas reglamentaciones que dan lugar a la disputa que nos ocupa se podrían resumir en los siguientes puntos:

1. que ninguno demande por Dios sin que sea examinado si es pobre.

2. que aunque sea pobre, nadie pida sino en su naturaleza, dentro de ciertos límites, salvo si fueses en caso de pestilencia o de grave hambre. 
3. que esos mismos en su naturaleza no pueden pedir sin cédula del cura o del diputado.

4. que estas cédulas no se las den sin que sean primero confesados, como lo manda la Iglesia.

5. que los peregrinos que vayan a Santiago no puedan salir a pedir más de cuatro leguas del camino derecho.

6. que, porque si pudiese hacer que los pobres se alimentasen sin que anduviesen a pedir por las calles, los provisores y regidores tuviesen cuidado, cada uno en lo que tocase a su oficio, y pusieren diligencia cómo los hospitales dotados se reformasen, para que allí fuesen alimentados y curados. (Carro, 1943, p. 40)

Ds fue muy crítico de las disposiciones que se contenían en la instrucción, mientras que JR defendió las nuevas leyes de los pobres y es un claro ejemplo de la influencia del humanismo europeo en los reformistas españoles.

\section{La crítica de Domingo de Soto}

En primer lugar, Ds critica la regulación. Al igual que sus coetáneos, considera necesario diferenciar entre pobres verdaderos y falsos, pero a diferencia de ellos y en contra de la tendencia al castigo a los ociosos, criticó la dureza de las nuevas formas jurídicas, encargadas de reprimir el vagabundeo, y defendió otros controles más laxos para evitar males mayores como el incremento de delitos contra la propiedad (Soto, 2006).

En segundo lugar fue crítico con las prescripciones, sobre todo las contenidas en la Instrucción, que era lo más cercano en el tiempo, que concernían al trato que tenía que ser dispensado a los extranjeros pobres y peregrinos. No cabe duda de que la intención de las autoridades públicas era la de evitar desplazamientos de los pobres, facilitar su identificación e impedir el asentamiento de los extranjeros pobres. Ds defendió precisamente lo contrario, porque "todo el Reino es un cuerpo y no debe existir distinción entre los hombres por razón de su procedencia y tampoco impedir que haya solidaridad entre las tierras ricas y las pobres"(Soto, 2006, p. 12). Además de los sujetos, la prohibición afectaba también el desarrollo de las funciones específicas de las órdenes mendicantes, ya que a partir de ese momento, el poder civil y el eclesiástico se repartirían el control.

Este tema de la limitación de movimientos preocupó bastante a DS, no así a JR, que debía su influencia a Luis de Vives. Probablemente, las dimensiones del problema al que se enfrentaban las autoridades castellanas eran mucho más alarmantes que en los Países Bajos. El filósofo valenciano defendió la repatriación de los extranjeros pobres, mediante una ayuda económica, si fuera preciso, de acuerdo con las leyes del derecho civil de entonces. La única excepción que 
admitió fue en caso de guerra, pues bajo esta circunstancia debían ser acogidos como si fueran naturales.

En tercer lugar, la crítica de Ds se centra en el sistema de reparto de la limosna. Es un fenómeno característico de la vida social española de entonces la confusión entre derecho y religión. Para recibir la limosna, los pobres debían confesar y haber recibido la comunión. Ds ve este imperativo legal como una aberración teológica (Soto, 2006).

El hecho de prohibir mendigar implica también un cambio en la forma de realizar la limosna, y fue interpretado por ds como una medida adoptada por un movimiento social y político contrario a los pobres. La presencia física de los pobres pidiendo limosna por la calle era, para él, algo imprescindible para promover la caridad, lo que lo obligaba a estar en contra de cualquier manera de encerramiento de los pobres o de limitación de sus movimientos. No desconocía la complejidad de la distribución de los bienes a los pobres, y por ello acudía a la prudencia y al consejo de personas ecuánimes que pudieran ayudar a los obispos en estas tareas y en sus decisiones.

\section{El planteamiento de Juan de Robles}

Al comenzar su escrito, JR consideró necesario aclarar que los argumentos que él iba a exponer contra la mendicidad no debían interpretarse como un ataque a la labor que hasta entonces hacían las órdenes mendicantes. Acudiendo a la doctrina de Santo Tomás de Aquino, defendió la existencia y la misión de aquellas personas que voluntariamente vivían en la pobreza, sustentándose de las limosnas de los demás. Pero lo que pretendía era argumentar que "era mejor que nadie tuviera necesidad de mendigar" (Robles, 1545, p. 17), y sugería un nuevo modelo asistencial, a través de la realización de colectas y una adecuada repartición a los pobres. Este modelo requería un mínimo de organización y de buen funcionamiento; por eso, JR se refería a tres roles: los administradores - elegidos entre las autoridades municipales o del cabildo-, los receptores que tenía que dar cuenta de su trabajo mensualmente- y los ejecutores - que tendrían la obligación de perseguir al falso mendigo-.

Aunque este plan asistencial pudiera ser criticado, comenta JR en su propio escrito, por su novedad, le parecía que era necesario adaptarse a los nuevos cambios sociales, siempre que fueran honestos y que sirvieran para remediar, como en este caso, las necesidades de los demás. Y más que entrar en el debate sobre si las cantidades recaudadas resultarían o no suficientes, entendió que la mejor defensa era poder comprobar que no era tan escaso el número de personas caritativas, pues los pobres habían disminuido con respecto a épocas anteriores.

El prohibir mendigar, con la correspondiente falta de libertad, era justificado por JR por el bien común. El problema es que dejaba en manos del poder político la decisión sobre la restricción y límite de las libertades de los demás. La potestad 
gubernativa se podía convertir en arbitraria, con la consiguiente posibilidad de abusos. Frente a las acusaciones sobre el trato dispensado a los peregrinos y extranjeros, JR negó que existiera una limitación preestablecida, y más bien les sugería ver al administrador para que les concediera una licencia para recibir una cantidad o para poder alojarse en alguna posada pública (Robles, 1545, p. 50).

\section{Análisis de la doctrina de Domingo de Soto y Juan de Robles y relación con la situación actual}

La relación entre la prohibición de la mendicidad en el siglo xvi y el trato dado en la actualidad a los inmigrantes económicos y a los refugiados no es tan forzada, como a primera vista pueda parecer, por el espacio de tiempo que las separa. En este punto, se trata de ver las semejanzas que pueda haber entre ambas y si las soluciones propuestas en su día pueden servir para dar luces, $\mathrm{o}$ al menos paliar la crisis actual. En ambos casos no se trata de hechos aislados, sino de una numerosa población que se ve obligada a mendigar o trasladarse de ciudad o de país para sobrevivir (Bondolfi, 1985).

A partir del siglo xvi Europa vive un pauperismo de masas, uno de los motivos por los que los humanistas de la época empiezan a ver un problema de orden social que hay que solucionar, y las distintas leyes de los pobres son reflejo de ello. A nadie se le escapa, ahora ni entonces, que "muchas veces esas leyes tenían un contrapunto que era que iban acompañadas de la represión del débil, lo que preparó el campo para el debate a pesar suyo" (Santolaria Sierra, 2003, p. 11).

No es lo mismo inmigrante que refugiado, ni lo son los derechos en el país de acogida, pero, desde el punto de vista que se ha adoptado en este trabajo, tienen muchos aspectos comunes los llamados inmigrantes económicos - que migran sin tener garantizado un trabajo ni su sostenimiento - y los refugiados. Coinciden en la situación que dejan atrás, de extrema carestía y necesidad. En el caso de los refugiados, puede decirse que su vida corre más peligro, aunque no se puede menospreciar la situación de algunos inmigrantes, como los procedentes del Magreb.

En este punto se establecen analogías entre las dos sociedades en torno a dos ideas: 1) la asistencia que se debe otorgar a los desfavorecidos - después de analizar si esa ayuda, sea privada o estatal, coopera o colabora a su descrédito social - y 2) el uso o destino universal de los bienes y del uso de lo común en ambas sociedades, en el siglo xvi y en la actualidad.

\section{Descrédito social del pobre. Asistencia pública o caridad privada}

En el trabajo de Ds se advierte la conciencia que tiene del descrédito social creciente del pobre, ya que él intuye que las medidas propuestas no buscan el 
remedio a las necesidades de los desfavorecidos ni son motivadas por la piedad, sino más bien por el cansancio respecto a esa situación. Suenan a lo largo de su tratado denuncias de la injusticia social y del ataque a la libertad que se perpetra hacia los pobres (Soto, 2006). Junto a la sensibilidad indudable del dominico, hay que pensar que esta crítica se encuentra en sus profundas convicciones acerca de la libertad individual y en su concepto de persona. De ahí deriva también su convencimiento de que si es la persona la que está en extrema necesidad, los bienes tienen un uso universal.

En las páginas de Soto se advierte la conciencia que tiene del creciente descrédito social del pobre y comentarios sobre la intención de las medidas que se quieren adoptar. Soto no ve en ellas la piedad ni la búsqueda de un remedio, sino el hastío hacia esas situaciones de pobreza, e incluso el odio. Suenan a lo largo del tratado denuncias de injusticia social y ataques contra la libertad.

El debate que se plantea en ambas obras, la de DS y JR, no se puede reducir al enfrentamiento entre una supuesta mentalidad medieval (DS) y una mentalidad moderna (JR) sobre la cuestión de la pobreza. Ds no está al margen de la realidad, sabe ver los grupos depauperados y su inadaptación social, y vislumbra la dificultad para dar con la solución válida a un problema que no es solo algo personal, sino que encierra también una injusticia política y social. Tampoco la defensa que hace de los pobres se puede encerrar exclusivamente dentro de lo teológico o escriturístico, sino que se abre a derechos naturales de la condición humana.

$\mathrm{JR}$, por su parte, es un claro precursor de la reforma humanista en las estructuras sociales, y defiende la necesidad de intervenir, en nombre de la sociedad y del Estado, frente a los derechos individuales de las personas o de los grupos, todo esto desde la concepción de grupos representativos del nuevo orden social y político que va a conformar la sociedad moderna. Si bien reconoce que algunos de los pobres pueden llegar a fingir su pobreza, las injurias que sufren los auténticos no justifican las medidas que se quieren adoptar. El tono crítico hacia las clases acomodadas es una constante en su obra (Soto, 2006).

En definitiva, aunque os acepta la licitud de castigar al pobre que finge y la de socorrer al verdadero, defiende al pobre de una política que atenta contra su libertad y sus derechos individuales, y critica las medidas de reclusión, a la vez que defiende la libertad de mendigar. JR, por el contario, se inclina por una supresión total de la mendicidad, bien porque al verdaderamente necesitado se le cubren todas las necesidades, bien porque al que finge se le niega la asistencia y se le obliga a trabajar. El deber de trabajar será para él un supuesto totalmente asumido (Robles, 1545).

A la luz de estas leyes, es posible preguntarse si es nuestra sociedad, la actual, una sociedad decente, en los planteamientos que está llevando a cabo para solventar la crisis de los inmigrantes. Esa decencia radica en una no humillación, por parte de las instituciones a las personas a través de sus leyes. En el caso que 
nos concierne, "es más prioritario eliminar la humillación que ofrecer respeto" (Margalit, 2009, p. 17). ${ }^{2}$

Las leyes de inmigración en Occidente, por un lado, es claro que no quieren conculcar los derechos fundamentales del inmigrante, pero al mismo tiempo son un intento de preservar el estado de bienestar. Y no se puede olvidar que en los orígenes del concepto de bienestar está precisamente la idea de erradicar el tratamiento humillante a los desfavorecidos.

El problema estriba en si Occidente está dispuesto a disminuir algo sus parámetros de estado de bienestar por el desfavorecido y necesitado. Si se observa con atención, la idea de clasificar a los pobres en las leyes del siglo xvi tiene mucho que ver con la humillación porque, en el fondo, se está pretendiendo usar esta como elemento disuasorio para pedir ayuda. Las leyes de los pobres contaban con un elemento educador, para que los pobres perezosos fueran adquiriendo el hábito del trabajo y solo los que fueran verdaderos gozaran de la ayuda. Es decir, los que eran verdaderos eran sometidos a pruebas para cerciorarse de que no era fraudulenta su necesidad. En el actual estado de bienestar, esas pruebas humillantes como elemento disuasorio a la demanda de ayuda siguen existiendo. "Se supone que un sociedad de bienestar no solo mejora la humillación institucional, sino también las condiciones de vida degradantes como el desempleo, que normalmente no responde a una planificación" (Margalit, 2009, p. 177).

No todas las situaciones de infortunio se deben juzgar como humillantes, puede haber determinadas situaciones que han sido provocadas por la acción del hombre, pero que no llevaban en sí la intención de humillar a nadie. En este sentido, ¿se puede eliminar de la pobreza - que es el tema que nos ocupa - la humillación? Solo en el caso de que sea acogida voluntariamente, por ejemplo en el caso de los monjes budistas o cristianos.

Una de las consecuencias que tuvo la ley de los pobres en los distintos países de Europa fue atribuirles a ellos la culpa de su situación. Sin embargo, los ciclos de la economía capitalista han dejado a demasiada gente fuera, como para que siga siendo creíble la afirmación de que la pobreza es fruto de una carencia moral, como lo es la pereza. Ver la pobreza como algo que cierra toda posibilidad de vivir una vida digna hace a los más desfavorecidos verse todavía más incapaces. "Es altamente probable que el fracaso se vea como totalizante, como si hubieran fracasado como seres humanos, lo cual resulta todavía más humillante" (Margalit, 2009, p. 181) . El estado de bienestar intenta eliminar la humillación, primero, a través de la abolición de las condiciones degradantes de la pobreza - al menos mitigarlas - , y, segundo, a través del exterminio de la pobreza, sin incurrir en la lástima, que es lo que ocurre a veces en la sociedad caritativa.

2 No pretendo en estas páginas entrar en la valoración que hace este autor del calificativo de decente como de carácter macroético. Más bien me centro en lo que él llama la "humillación institucional", por considerarlo especialmente relevante para la reflexión de esas páginas. 
Von Mises (1943) vio cierto paralelismo entre los funcionarios del estado de bienestar y las personas que ejercían la caridad, ya que en ambos veía una humillación hacia los indigentes. ¿Hay tanta semejanza entre el filántropo y el funcionario? Bajo esta perspectiva, se supone que en el estado de bienestar hay una gran parte de burocracia, y la diferencia entre ambas sería la motivación del donante, uno por benevolencia y el otro por obligación. En el caso de la sociedad del bienestar, los receptores de la ayuda serían humillados cuando los funcionarios actuaran benévolamente ante algo que ellos perciben por derecho. En ese caso, es posible preguntarse si la sociedad caritativa respeta más la dignidad de la persona, ya que no es por vía impositiva, sino por donación voluntaria. En ese caso, tampoco se estaría exento, aun en el caso de la sociedad caritativa ideal, de no humillar al receptor. De otras muchas maneras se puede comparar la sociedad del bienestar con la caritativa, aunque la humillación haya sido el punto de atención en este aparte, siguiendo el estudio que hace Margalit (2009).

Por ejemplo, se puede analizar la diferencia entre estas dos sociedades estudiando el caso del paro o desempleo. En nuestra sociedad, el trabajo es una condición vital para la dignidad de la persona, algo de lo que no se puede privar a las personas sin degradarlas. Normalmente la gente considera valioso el trabajo si este le permite ganarse la vida sin depender de la voluntad de los demás (Ceccherini, 2008). El trabajo confiere a las personas autonomía. Pero, ¿se debe garantizar a cada uno el empleo que desee? La obligación nace de entender al hombre como ser que trabaja. De ahí la humillación del desempleo involuntario y la percepción de rechazo social.

En el siglo xvi el trabajo se consideraba una terapia para salir de la pobreza, no se planteaba la imposibilidad de no conseguirlo o la posibilidad del paro forzoso, como sí ocurre en nuestros días. Es ciertamente negativo que la sociedad no permita que una persona consiga el trabajo que le satisfaga. Es cierto, sin embargo, que la sociedad del bienestar no está obligada a que todos tengan, por su trabajo, unos ingresos mínimos, pero sí a proporcionar ocupaciones con sentido, por ejemplo la posibilidad de estudiar.

Otro punto de estudio podrían ser las diferencias que hay entre los rasgos de identidad o de realización que afectan a la hora de la estima social y personal de todos, pero sobre todo, de los más desfavorecidos. Avergonzar a una persona cuyos rasgos de identidad son legítimos es una humillación, pero también puede ser un insulto avergonzarla de los aspectos adquiridos. No todos los elementos de la propia autodefinición son igualmente relevantes, pero sí son de gran importancia las características de pertenencia. Con todo, la humillación en este tema, incluida la institucional, está muy extendida. La ridiculización o la discriminación son a menudo causa de perjuicio para que las personas que pertenecen a esos grupos, y que se identifican a través de ellos, se sientan heridas. "Una sociedad decente es aquella que no rechaza a los grupos incluyentes moralmente legítimos" (Margalit, 2009, p. 118). 
Señalar que una sociedad justa puede actuar con malos modos puede parecer una insignificancia, porque es confundir la ética con una cuestión menor de etiqueta, pero no lo es, porque refleja un temor a que la justicia no se convierta en compasiva o en vengativa. El exigir que una sociedad justa sea decente significa que no solo basta con distribuir los bienes de un modo justo, sino que también hay que velar por el talante con el que se distribuyen.

"La humillación es un concepto que se basa en un contraste, y lo opuesto a la humillación es el concepto de respeto hacia los humanos. Si no hay dignidad humana, no hay tampoco concepto de humillación" (Margalit, 2009, p. 124). Esta percepción es nuclear para el ser humano, sea de la época que sea.

\section{Los conceptos de comunidad de bienes y de propiedad privada}

En el apartado anterior se ha analizado el descrédito social del desfavorecido que puede ocasionar la asistencia, según Ds y JR, en comparación con la realidad de hoy. En este apartado se va a revisar, en la doctrina de DS y JR, la cuestión de la propiedad privada, en contraposición al uso común de los bienes, tema clave en estos autores, cuando exponen la asistencia social. Se compara de nuevo con la situación actual.

El tema de la propiedad privada y la comunidad de bienes constituía, en el siglo Xvi, un tema especialmente problemático, envuelto en controversias teológicas y políticas ya antes de que Ds escribiera su tratado. De todas las ideas teológicas, sociales, políticas y económicas defendidas por los reformistas, las relativas a la comunidad de bienes, concebida como alternativa a la propiedad privada, fueron especialmente polémicas "por su carácter revolucionario y perturbador del orden político y jurídico de las sociedades modernas de aquel momento" (Garrán Martínez, 2004, p. 86).

La defensa de la propiedad privada frente a la alternativa de la posesión en común no le impide a Ds defender que, en lo que se refiere al uso de las riquezas, se practiquen las virtudes de la liberalidad y de la misericordia en la asistencia a los pobres. En las situaciones de extrema necesidad existe, por parte del pobre, un derecho que le asiste a usar los bienes. Este derecho, siguiendo a Santo Tomás, es de derecho natural. Cuando habla del derecho de la propiedad privada, lo califica de "derecho de gentes", también siguiendo al Aquinate. Esta calificación no confronta un derecho con otro, ya que para él, los derechos de gentes son deducidos de principios naturales gracias al uso de la razón. Cuando uno se encuentra en situación de extrema necesidad y existen bienes superfluos, surge el deber de compartir, deber basado en el derecho que tienen todos los hombres, especialmente los pobres, de poder disfrutar de todos los bienes creados (Amat, 1994). 
Aunque defendió también que era conveniente que las riquezas se poseyeran particularmente, a fin de que cada uno pudiera conocer lo que es suyo y respetara así lo que es de los demás, afirmó que "en cuanto al uso, la misericordia y la liberalidad deben hacerlas comunes, de modo que, quien tenga de sobra, reparta con quien tiene necesidad" (Soto, 2015, 2, q. 3, a. 11). Se ve también aquí la influencia de la escuela de Salamanca. En ella se defendió que el dominio común es un derecho natural, que no es otra cosa que compartir lo que se posee, en propiedad privada, con otros en tiempos de necesidad. Los hombres solo debemos tener lo necesario y repartir el resto con los necesitados en momentos de escasez. De hecho, este será uno de los argumentos principales de Francisco de Vitoria, al defender el derecho de gentes en la conquista española del Nuevo Mundo. "Este derecho sobre todas las cosas tiene especial relevancia en situaciones particulares, una de ellas es cuando los hombres se encuentran en estado de necesidad" (Añaños, 2013, p. 108).

Ds, en un tono parecido al de Vitoria, hablará de derechos y deberes naturales, entre los que sobresalen como fundamentales los derechos de propiedad. El derecho natural, según el dominico, autoriza para usar las cosas inferiores al hombre en beneficio propio, pero no dice el modo de hacer efectivo ese dominio. Por decirlo de algún modo, el derecho natural es mudo bajo este aspecto, al hombre le toca hallar el modo más apto. La división de la propiedad es para él lícita, porque con ella el hombre se muestra más solícito, más ordenado y más pacífico; es algo humano, pero de carácter universal - afirma, siguiendo de nuevo al Aquinate-. "Pero el uso de las cosas debe ser tal que pueda ser compartido" (Soto, 2015, 2, q. 3, a. 11).

Por este motivo, albergaba Ds serias dudas de que se pudiera prohibir a los pobres legítimos salir a mendigar, porque equivalía a obligarles a pasar necesidad injustamente. Idéntica libertad de movimientos reivindicaba para el peregrino, sobre todo si era extranjero. No negaba que el trasiego de peregrinos ocasionara problemas, pero le parecían tan pocos, numéricamente, los que mendigan en suelo extranjero, que no consideraba necesaria la expedición de una ley para regularlos (Soto, 2006). Concluía que no es lícito a ningún poder político restringir la libertad a ningún necesitado. Para Soto, el dominio sobre las cosas o el derecho de propiedad privada no es un derecho absoluto, sino relativo y limitado al bien común de toda la sociedad.

Sin la división de la propiedad, desaparecería la virtud de la liberalidad, que es el justo equilibrio entre tacañería y prodigalidad. El que no tiene nada propio no puede ser generoso. Por el contrario, el que lo tiene todo no necesita de la generosidad de nadie, con lo que desaparecería el agradecimiento y la hospitalidad.

JR, al ser partidario de la intervención pública en la asistencia a los pobres, ve enormes ventajas en esa ayuda. En concreto, respecto a la razón y crítica nuclear de Soto de que no se puede privar a los pobres de la libertad sin culpa suya, JR afirma que los poderes públicos pueden hacerlo en beneficio del bien común. Por lo tanto, la orden que prohíbe mendigar a los que pueden trabajar es justa, 
a su juicio, porque esta clase de gente constituye un peligro para la sociedad. Además, con ello se evitan contagios de enfermedades y que los hijos de estos mendigos se críen en una ociosa libertad.

JR se adhería con estas afirmaciones a la corriente de modernidad de Vives y a las teorías de la Reforma, que quitaban a la Iglesia la labor de asistencia para ponerla en manos de los poderes públicos, pero no las defendía tanto por afinidad ideológica, sino por motivos legales y porque le parecía que serían más eficaces para el socorro de los pobres (Del Vigo Gutiérrez, 2006). Aunque Ds no le replicó directamente, su obra De iustitia et iure fundamenta los derechos y deberes individuales en la propia persona humana, que es, por su categoría, anterior al Estado. El hombre tiene una personalidad propia independiente del Estado y es sujeto de derechos. No hay, por lo tanto, paridad posible (Soto, 2015).

JR intentó justificar la supresión de la libertad de movimientos de los pobres y menesterosos, y aprovechar la necesidad en la que se encuentran para obligarles a su reforma moral. Se ve en él un cierto rigor innecesario y una mentalidad enraizada en los usos y abusos de las prácticas asistenciales medievales (Del Vigo Gutiérrez, 2005). Tanto Robles como De Soto “están todavía inmersos en una mentalidad de transición de lo medieval a lo moderno" (Santolaria Sierra, 2003, p. 39). El argumento de mayor calado en JR es la necesidad que tiene el Estado de mirar el bien público, y ello puede ser causa legítima para quitar las libertades a los pobres.

Uno y otro expresamente se dan cuenta no solo de las causas del problema, sino de que las soluciones posibles tienen que ir en la línea de respuestas cada vez más organizadas. Se diferencian, sin embargo, en que uno respeta más la libertad personal y le parece que la intervención estatal la conculcaría, y el otro, interpelado por la eficacia del resultado, propone medidas más coercitivas y estatales. Se trata de la ley de las personas frente a la ley de las naciones, si el todo vale más que las partes.

Este debate se puede trasladar a nuestros días, cuando se hace compatible un concepto de ciudadanía flexible, casi sinónimo de ciudadanía cosmopolita, con formas de exclusión a algunos ciudadanos en distintas variantes (Kymlicka, 1995). Es el caso de los refugiados, que no son acogidos con los mismos beneficios sociales que tienen el resto de los ciudadanos, por más que estén huyendo de países en guerra. Las obligaciones que emanan de la Convención de Ginebra de 1951, por ejemplo, nacen de este derecho de libertad y de entender el uso común de la tierra en caso de necesidad (Saulle, 1986). Por eso se prohíbe sancionar las entradas de refugiados que huyen de lugares donde su libertad o su vida se encuentran amenazadas. Pero aun así, "países miembros del Consejo de Europa, así como los Estados Unidos de América, observan una actitud restrictiva respecto de los solicitantes de asilo que huyen de guerras civiles" (Gortázar Rotaeche, 1997, p. 155). 
Desde siempre, tanto en el siglo xvi como en nuestros días, en ese derecho del peregrino han influido las características del país receptor. El Nuevo Mundo se ha caracterizado por ser un mundo de recién llegados, en el que encuentran un gran espacio vacío para hacer su patria. En cambio, el viejo mundo es, desde hace mucho tiempo, un mundo sin espacios, donde cuesta más la acogida.

Es preciso, en nuestros días, desenmarañar esta ambivalencia. Mientras las normas de esta ciudadanía son interpretadas como el estatus individual que protege a la persona, porque es titular de derechos en una sociedad civilizada, hay peligro de que se despierte un Estado soberano. En principio, este tándem - estatus individual y Estado soberano - no tendría por qué significar que uno reduzca al otro ni nos tendría que preocupar que la universalización de los derechos humanos pudiera ser usada para justificar intervenciones so capa de ser humanitarias (Benhabib, 2013). Sorpresivamente, los efectos de la globalización no solo se observan en la economía, sino también en la dignidad de la persona y en sus derechos, y aquellos no siempre son positivos.

\section{Reflexión final. A modo de conclusión}

¿Puede ser que, en democracia, al tener procedimientos formales comunes, pero no contenidos comunes, sea más difícil ponernos de acuerdo sobre qué hacer? Con sus limitaciones, en el siglo xvi se compartía un modo de pensar y un común acuerdo sobre lo fundamental y sobre los principios que sustentaban los derechos, de modo que la sociedad oscilaba entre libertad individual o intervención estatal, pero no había duda sobre el contenido de la dignidad de cada hombre. De hecho, DS y JR tienen sus divergencias, porque tienen sensibilidades distintas, pero no en lo fundamental. Es decir, "se compartía una ética racional de contenido universal e inmutable, que estaba por encima de la pluralidad cultural y de la diversidad social"' (Elósegui, 1998, p. 335).

El debate actual, al igual que el del siglo xvi, es un debate profundamente cristiano, porque Europa tiene sus raíces en el derecho romano y en la posterior implantación del cristianismo en el Imperio romano. Coinciden, además, los temas de debate: la inmigración y la pobreza, el derecho del peregrino a moverse y la asistencia que se le debe prestar. Hay que anotar que el hecho de que Europa sea un continente viejo, sin espacio y, por ende, cerrado - mientras que América nació como una Nación de nacionalidades (Pérez Madrid, 2004)—, afecta la toma de decisiones.

No podemos olvidar que el dualismo tan europeo entre la jurisdicción que debe tener lo espiritual y lo secular y el pluralismo político ha sido el corazón de la formación de la tradición legal de Occidente (Berman, 2009). Así como en el siglo XII y XIII ejerció enorme influencia, en la formación de las ideas, la Iglesia de Roma, en los siglos posteriores también lo hicieron el luteranismo alemán y el calvinismo inglés. Es importante ser conscientes de esta herencia 
de las distintas formas de fe cristiana, pues es el fundamento que subyace hoy en día en nuestras instituciones. Y si ahora podemos decir que en algo puede contribuir esta tradición, en el desarrollo de un mundo multicultural, es en la creencia en su capacidad de hacer evolucionar la ley para mantener, al mismo tiempo, continuidad en lo fundamental, pero adaptándose a los cambios sociales.

¿Hasta dónde está dispuesto a ceder, nuestro estado de bienestar, sus prestaciones para dar cabida a inmigrantes y refugiados? Existe un deber de ayudar al necesitado y de prescindir, por ayudarle, de los propios bienes, y no solo de los superfluos. Europa tiene que volver a sus raíces, a la idea ciceroniana - recogida en el derecho natural y en el derecho de gentes de la Escuela de Salamancade que el hombre puede y debe hacer uso de verdadera humanidad con otro ser humano.

Por eso, de las crisis, las sociedades salen fortalecidas, renovadas, si se saben resolver. Pueden servir para testar la resistencia de un grupo social, la altura de miras de una comunidad política, la calidad moral de un pueblo. Siempre se han concebido como tiempos de cambio, de regeneración, pero también de recuperación de ideales perdidos. La crisis de los refugiados podría ayudar a Europa a poner en práctica la enorme calidad moral de sus propios valores. La experiencia, dice un viejo refrán, es el maestro más caro. Sería una pena que el hombre de hoy en día no se contentara con experiencias ajenas. Es innegable que vivimos en un mundo que ha acortado las distancias y, al mismo tiempo, de crecientes diversidades, culturas, pueblos, etnias, religión. No es contradictorio que ambas cosas ocurran; más bien se han alimentado recíprocamente. Así, al hombre postmoderno le cuesta unificar esta fragmentación, y tal vez por el relativismo subyacente también a la posmodernidad, no sabe cómo ayudar a cada uno como se merece, y lo unifica del modo que cree que es mejor para él, pero sin atender a las necesidades del otro en cuanto otro. El escepticismo, el relativismo, el pensamiento débil, tan característico de nuestro tiempo, no parece el lenguaje adecuado para un diálogo respetuoso y fructífero. En este sentido, son encomiables algunas de las iniciativas que se están llevando a cabo. ${ }^{3}$

Acogiendo desinteresadamente al refugiado una sociedad supera las reglas del do ut des, de la pura y calculadora reciprocidad para convertirlas en un estimulante servicio al prójimo. Esta crisis es una oportunidad de oro para demostrar al mundo que la vieja Europa tiene todavía mucho que aportar. (Domingo, 2015)

Esta magnanimidad se contrapone a cualquier utilitarismo centrado en el propio interés y a cualquier excusa basada en burocracias inútiles. Lleva a tener una alta consideración de los demás e invita a la benevolencia, a la compasión, a

3 Por citar un ejemplo de los muchos que la creatividad humana está llevando a cabo en esta crisis, véase la iniciativa interconfesional (Comunidad de Sant'Egidio, junto con la Federación de Iglesias Evangélicas de Italia y la Mesa Valdense) junto al Gobierno italiano, en la frontera con el Líbano, donde unas oficinas se encargan de preparar las visas humanitarias. Véase http://www.lastampa.it/2015/09/14/...santegidio...acogida.../pagina.html. 
la solidaridad. Además puede ser aplicada no solo a las personas, en su singularidad, sino a todos los colectivos, en particular las comunidades políticas.

\section{$\boldsymbol{R}_{\text {eferencias }}$}

Comisionado de las Naciones Unidas para los Refugiados. (2015). Press coverage of the refugee and migrant crisis in the EU: A content analysis of five European countries. Recuperado de http://www.unhcr.org/cgi-bin/texis/vtx/ home/opendocPDFViewer.html?docid=56bb369c9\&query=statistics $\% 20$ refugiados $\% 202015$

Amat Lacroix, M. (1994). El derecho natural en Domingo de Soto. Roma: Athaenum Romanum Sanctae Crucis.

Añaños Meza, M. C. (2013). La doctrina de los bienes comunes de Francisco de Vitoria como fundamentación del dominio en el Nuevo Mundo. Persona y Derecho, (68), 103-137.

Benhabib, S. (2013). Dignity in adversity: Human rights in troubled times. Cambridge: John Wiley \& Sons.

Berman, H. J. (2009). Law and revolution: The formation of the Western legal tradition (Vol. 2). Cambridge: Harvard University Press.

Bondolfi, A. (1985). Dibattiti umanistici e teologicia ttorno al pauperismo nel xvi secolo. Studia Patavina. Rivista di Scienze Religiose Padova, 32(3), 515-529.

Carro, V. D. (1943). Domingo de Soto y su doctrina jurídica: estudio teológico-jurídico e histórico. Madrid: Hijos de E. Minuesa.

Ceccherini, E. (2008). La tutela della dignità dell' uomo. Nápoles: Editoriale Scientifica.

De Soto, D. (2006) Deliberación en la causa de los pobres. Salamanca: San Esteban.

De Soto, D. (2015). Tratado de la justicia y del derecho. Reus: Reus.

Del Vigo Gutiérrez, A. (2006). Economía y ética en el siglo xvi: estudio comparativo entre los padres de la Reforma y la teología española. Madrid: Biblioteca de Autores Cristianos.

Domingo, R. (2015, octubre 16). La crisis de los refugiados y la "humanitas". Recuperado de http://www.elespanol.com/opinion/20151015/71862815_12.html 
Elósegui, M. E. (1998). El derecho a la igualdad y a la diferencia: el republicanismo intercultural desde la filosofía del derecho. Madrid: Instituto de la Mujer.

Fatica, M., Dipartimento di filosofia e politica dell' Istituto universitario orientale. (1992). Il Problema della mendicità nell' Europa moderna: secoli XVI-XVIII. Nápoles: Liguori.

Garrán Martínez, J. M. (2004). La prohibición de la mendicidad. La controversia entre Domingo de Soto y Juan de Robles en Salamanca (1545). Salamanca: Universidad de Salamanca.

González Enciso, A. (1992). Historia económica de España moderna. Madrid: Actas.

Gortázar Rotaeche, C. J. (1997). Derecho de asilo y no rechazo del refugiado. Madrid: Universidad Pontificia Comillas, Dykinsons.

Kymlicka, W. (1995). Multicultural citizenship: A liberal theory of minority rights. Oxford: Oxford University Press.

Margalit, A. (2009). The decent society. Cambridge: Harvard University Press.

Mises, L. (1943). La omnipontencia gubernamental. Barcelona: Hermes.

Montoro, C., López, D., Pons, J. J. (2009). La inmigración internacional: motor de cambios sociodemográficos y territoriales. Pamplona: EunSA.

Pérez-Madrid, F. (2004). Inmigración y libertad religiosa: un estudio desde la Ley de Extranjería. Pamplona: Universidad de Navarra, Cátedra Garrigues.

Robles, J. de. (1545). De la orden que en algunos pueblos de España se ha puesto en la limosna para remedio de los verdaderos pobres. Recuperado de http://www. cervantesvirtual.com/obra/de-la-orden-que-en-algunos-pueblos-de-espana-se-ha-puesto-en-la-limosna-para-remedio-de-los-verdaderos-pobres/

Santolaria Sierra, F. (2003). El gran debate sobre los pobres en el siglo XVI, 1545. Madrid: Ariel.

Saulle, M. R. (1986). Saggi di diritto e di organizzazione internazionale. Nápoles: Giannini.

Vigo Gutiérrez, A. del (2005). La asistencia social y el socorro a los pobres en los padres de la reforma y en los teólogos españoles des siglo xvi: lección inaugural del curso académico 2004-2005. Burgos: Facultad de Teología del Norte de España.

Vives, J. L. (2007). El socorro de los pobres: la comunicación de bienes. Madrid: Tecnos. 